\title{
A Rare Case of Isolated Auricular Injury Caused by a Tree Branch During a Traffic Accident
}

\author{
Serhan Derin'1, Halil Beydilli², Leyla Şahan³', Ethem Acar², Murat Şahan'1, Selvet Erdoğan \\ 'Department of Otorhinolaryngology, Muğla Sıtkı Koçman University School of Medicine, Muğla, Turkey \\ 2Department of Emergency Medicine, Muğla Sıtkı Koçman University School of Medicine, Muğla, Turkey \\ 3Department of Anesthesiology and Reanimation, Muğla Sıtkı Koçman University School of Medicine, Muğla, Turkey \\ ${ }^{4}$ Clinic of Ear Nose and Throat, Vezirköprü State Hospital, Samsun, Turkey
}

\section{ABSTRACT}

Introduction: Penetrating head and neck trauma associated with road accidents can cause significant morbidity and mortality because the neck contains many important structures of the vascular, respiratory, digestive, and neural systems.

Case Report: In the present report, we present an example of a penetrating head and neck trauma caused by a tree branch, commencing in the temporal region and extending from the external auditory canal and retromandibular area during a car accident.

Conclusion: In such cases, isolated auricular and external auditory canal injury is uncommon, and the aim should be to protect the integrity of the channel wall.

Keywords: Auricle, penetrating, head trauma

Received: 29.05.2015 Accepted: 21.12.2015 Available Online Date: 04.02.2016

\section{Introduction}

Traffic accidents represent an important component of emergency admissions, and many different injuries are noted. The average number of traffic accidents has been about 1.1 million annually over the last 5 years in Turkey; of these, approximately 140.000 were fatal (1). Head and neck injuries are the most common cause of death. In cases of head and neck injuries that cause morbidity, most involve drivers and frontseat passengers $(2,3)$. In the present report, we present a rare isolated example of a penetrating neck trauma caused by a tree branch during a car accident, commencing in the temporal region and extending from the external auditory canal and retromandibular area.

\section{Case Report}

A 23-year-old male patient with a head injury caused by a tree branch during a car accident was admitted to our emergency room. On physical examination, his circulatory system, respiratory system, cranial nerves, and central nervous system were normal. On head and neck examination, part of a tree branch had entered the right auricle superiorly, covering the external auditory canal, and reaching the retromandibular area (Figure 1a, b, and c). There was no active bleeding. On otoscopic examination, the tympanic membranes were bilaterally normal. The foreign body filled the right external auditory canal and attained the retromandibular area, as observed using Computer Tomography (Figure 2). The patient said that he had not been wearing a seat belt at the time of the accident. The branch had broken in through the vehicle's window.

The patient was operated on under general anesthesia. The superficial temporal artery commenced active bleeding after the foreign body was removed; the bleeding was controlled. The wood had entered the auricle superiorly and had completely separated the external auditory canal from the bone cartilage junction. The wood had moved the mastoid bone anteriorly and the 

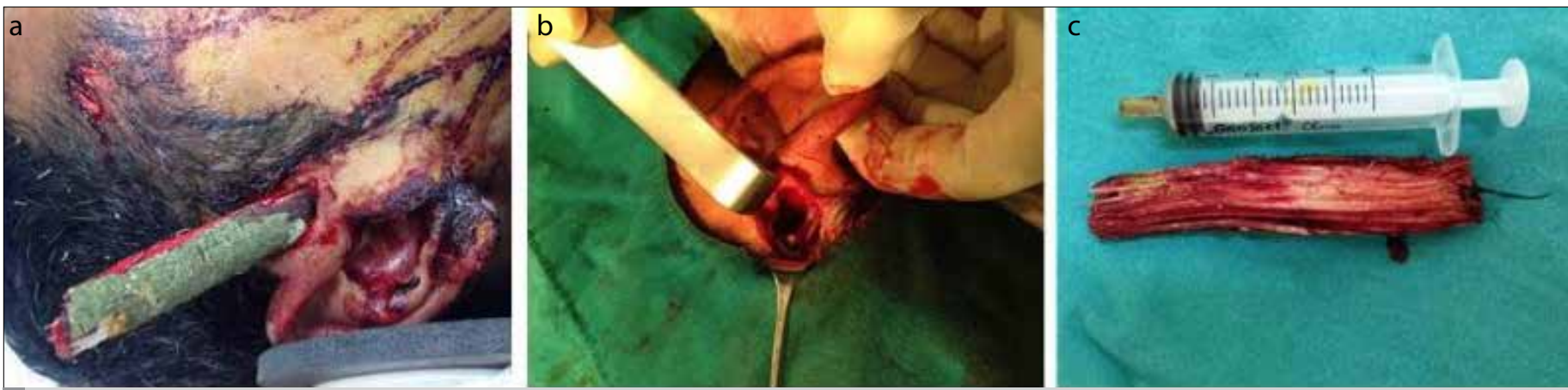

FIGURE 1. a-c. Piece of wood penetrated superiorly in the auricle (a); injury site (b); and the piece of wood after removal (c).

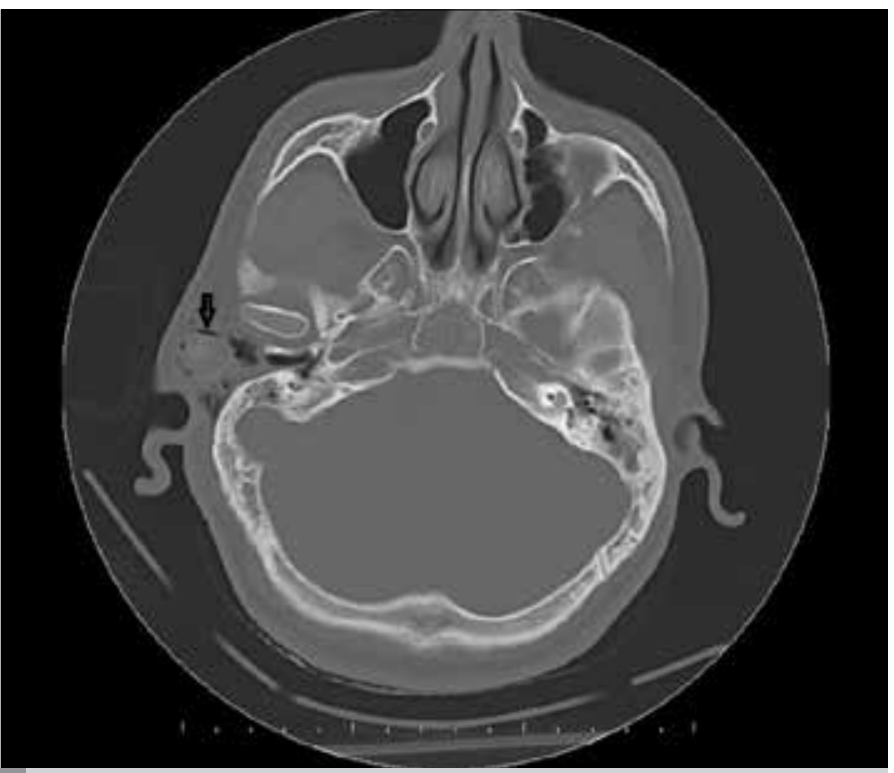

FIGURE 2. A foreign body isodense with fatty tissue as observed using $C T$.

parotid gland superficial lobe posteriorly; further, it had extended to the retromandibular area. The retromandibular vein and auricularis magnus nerve were intact. Pieces of wood were removed from the site of injury. Dead tissues were debrided. The conchal and tragal cartilage fragments that were open were positioned under the external auditory canal skin without suturing. The wound was washed with saline and rifampin sodium. Because the outer ear canal was separated from the bone canal, it could not be sutured. The external auditory canal was filled with a sponge and was allowed to recover.

A $38^{\circ} \mathrm{C}$ fever developed on the first postoperative day but soon resolved. Duocid ( $4 \times 2 \mathrm{~g}$ ) was administered for 7 days and amoxicillin/ clavulanate $(2 \times 1 \mathrm{~g})$ for the following 7 days. A cover was placed on the ear for 2 weeks to protect the integrity of the external auditory canal. Ciprofloxacin ear drops were applied locally onto the ear wick. A slight narrowing of the external auditory canal was evident at the cartilage-bone junction 2 months postoperatively. An audiological evaluation revealed normal results. There was no additional pathological finding.

Informed patient's consent form was obtained.

\section{Discussion}

Traffic injuries are a problem worldwide. According to World Health Organization data, 1.2 million deaths and 50 million injuries occur each year because of traffic accidents (4). Helmet use reduces the risk of injury in motorcycle accidents (5), whereas seat belt use reduces the risk of injury in automobile accidents.

Although knife and gun injuries are the most common causes of penetrating neck injuries, various other objects and situations have been reported in the literature (6). One type of such injury, broken glass or foreign bodies entering from the outside, may cause head and neck injuries in automobile accidents. In our case, a piece of wood broke through the window of the automobile and entered the body superior to the right auricle, which is a rare situation. Penetrating head and neck trauma in connection with road accidents can cause significant morbidity and mortality simply because the neck contains many important structures of the vascular, respiratory, digestive, and neural systems $(2,3)$. Furthermore, complications such as infections caused by foreign body injuries can occur. The neck injury extended to the retromandibular area in our case. The auricular artery, retromandibular vein, and auricularis magnus nerve were not damaged in this area. To prevent infection, we treated the patient with intravenous Duocid $(4 \times 2 \mathrm{~g})$.

Despite improvements in imaging technologies and surgical methods, penetrating injuries to the head and neck by impacted foreign bodies are very challenging because of the proximity to vital structures and/or difficulties in accessing the foreign bodies for removal. It can be difficult to determine the extent of the injury with a tree branch because fatty tissue and wood are approximately isodense on CT examination (7). In our patient, the external auditory canal was blocked by the wood, and an isodense image extended to the retromandibular area as observed in CT examination.

The auricle is an organ located between the dense anastomosis of the superficial temporal artery and the posterior auricular artery (8). This anastomosis allows the use of various local auricular flaps in surgical treatment and increases the chances of surgical success. In our case, we are of the view that the anastomosis extended seamlessly throughout the external auditory canal because of the extensive vascularity. Thus, the external auditory canal had separated from the bone border; a supporting sponge was used to allow primary heal- 
ing. This was preferred because the outer ear bone canal skin is very thin; therefore, it could not be sutured. In fact, to elevate the tympanomeatal flap during tympanoplasty, a skin incision is performed in the bone canal along a similar path. In our case, a total separation of the external auditory canal skin was observed, whereas during tympanoplasty, the separation is less than $50 \%$.

\section{Conclusion}

Protecting the integrity of the channel wall afforded a fairly good recovery in a case of total external auditory canal traumatic separation. In addition, many postoperative complications can be avoided or prevented during surgical removal of the foreign objects in penetrating neck injuries via the control of the major vascular and neuronal structures.

Informed Consent: Written informed consent was obtained from patient who participated in this case.

Peer-review: Externally peer-reviewed.

Author Contributions: Concept - S.D., L.Ş., H.B.; Design - S.D., L.Ş., H.B.; Supervision - S.D., S.E., E.A., M.S.; Data Collection and/or Processing - S.D., H.B., L.Ş., E.A., M.Ş., S.E.; Analysis and/or Interpretation - S.D., H.B., L.Ş., E.A., M.Ş., S.E.; Literature Review - S.D., H.B., L.Ş., E.A., M.Ş., S.E.; Writer -S.D., H.B., L.Ş., E.A., M.Ş., S.E.; Critical Review - S.E., E.A., M.Ş.

Conflict of Interest: The authors declared no conflict of interest.
Financial Disclosure: The authors declared that this study has received no financial support.

\section{References}

1. Turkey Statistical Institute, Road Traffic Accident Statistics. 2013. p. 18510.

2. Luqman Z, Khan MA, Nazir Z. Penetrating pharyngeal injuries in children: trivial trauma leading to devastating complications. Pediatr Surg Int 2005; 21: 432-5. [CrossRef]

3. Kaya KH, Koç AK, Uzut M, Altintaş A, Yeğin Y, Sayın I, et al. Timely management of penetrating neck trauma: Report of three cases. J Emerg Trauma Shock 2013; 6: 289-92. [CrossRef]

4. Dongo AE, Kesieme EB, Eighemherio A, Nwokike O, Esezobor E, Alufohai E. Motorcycle Related Injuries among Rural Dwellers in Irrua, Nigeria: Characteristics and Correlates. Emerg Med Int 2013; 2013: 569103. [CrossRef]

5. Lam C, Lin M, Chu S, Tsai S, Bai C, Chiu W. The Effect of Various Types of Motorcycle Helmets on Cervical Spine Injury in Head Injury Patients : A Multicenter Study in Taiwan. BioMed Research Int 2015; 2015: 487985. [CrossRef]

6. Rao LP, Peter S, Sreekumar KP, Iyer S. A "pen" in the neck: an unusual foreign body and an unusual path of entry. Indian J Dent Res 2014; 25 111-4. [CrossRef]

7. Abdulbaki A, Al-Otaibi F, Almalki A, Alohaly N, Baeesa S. Transorbital craniocerebral occult penetrating injury with cerebral abscess complication. Case Rep Ophthalmol Med 2012; 2012: 742186. [CrossRef]

8. Özçelik D, Unveren T, Toplu G. Subtotal ear amputation with a very narrow pedicle : a case report and review of the literature Çok dar pediküllü bir subtotal kulak amputasyonu : Ulus Travma Acil Cerrahi Derg 2009, 15: 306-10. 